\title{
Adoption of online education channel during the COVID-19 pandemic and associated economic lockdown: an empirical study from push-pull-mooring framework
}

\author{
Bishwajit Nayak $^{1,3}$ (D) Som Sekhar Bhattacharyya ${ }^{2} \cdot$ Shaileshwar Goswami $^{3}$. \\ Shreyash Thakre ${ }^{3}$
}

Received: 20 February 2021 / Revised: 14 May 2021 / Accepted: 5 June 2021 /

Published online: 10 June 2021

(C) Beijing Normal University 2021

\begin{abstract}
The purpose of the research was to study how the onset of COVID-19 pandemic fuelled shift towards digitalization in the education ecosystem. The study consisted of responses from 316 engineering students collected during the COVID19 pandemic physical lockdown in India from March to May 2020. The collected data was analysed using structural equation modelling to develop a model for online education in the study context based upon the push-pull-mooring framework. Hayes' model was used to analyze the effect of the multiple mediators to understand the relationship between the antecedents (Platform knowledge scope, alternative media attractiveness and normative environmental pressure) and switching behaviour for performance. This research contributed to the push-pull-mooring framework theory in the context of a crisis event.
\end{abstract}

Bishwajit Nayak

bnayak0107@gmail.com

Som Sekhar Bhattacharyya

somdata@gmail.com

Shaileshwar Goswami

goswamishaileshwar@gmail.com

Shreyash Thakre

shreyashthakre31@gmail.com

1 Narsee Monjee Institute of Management Studies (NMIMS), Mumbai, India

2 National Institute of Industrial Engineering, NITIE Campus, Faculty Room No -614, ALB, Mumbai 400087, India

3 National Institute of Industrial Engineering, NITIE Campus, Mumbai 400087, India 
Keywords COVID-19 pandemic · Physical lockdown - Online education channel · Push-pull-mooring framework · Technology adoption · Technology usage

\section{Introduction}

Human beings have been a creature of habit and they enjoyed being placed in zones of comfort (Ersche et al., 2017). However, events and technological progress often triggered switching behaviour amongst individuals (Firth et al., 2019). The world witnessed an unprecedented crisis in the form of the COVID-19 pandemic and its associated economic and physical lockdown (Ozili \& Arun, 2020). Students were particularly affected because educational institutions were closed immediately due to administrative lockdowns imposed to contain the spread of the COVID-19 pandemic (Sintema, 2020). From the realm of physical classroom education, students were suddenly exposed to the domain of online digital education (Oerther \& Peters, 2020). In certain cases, the students were mandated to undergo an online format of the educational institutes they were part of (Hodges et al., 2020). Moreover, many students during the months-long lockdown switched to online education course bundles beyond the mandated call of duty (Bozkurt et al., 2020). The authors recognized this unique transformation of a student's choice to a student's necessity in the COVID-19 crisis period, mandating the switch towards online education channels. As much of the extant literature was based on the physical model of education, it was important to study how students adopted online education channels and switched away from the physical education system. In this research, the authors applied the Push-pull-mooring (PPM) theoretical framework to explore and replicate this phenomenon (Bansal et al., 2005; Chen \& Keng, 2019). The study consisted of responses from 316 engineering students who were using multiple online education platforms such as Coursera (Narang et al., 2021), edX (Narang et al., 2021), Udemy (Yazdanian et al., 2020), NPTEL (Dutta, 2020), and such others apart from their institute-specific online platforms. The collected data was analysed by using structural equation modelling to develop a model for online education in the study context (Lin et al., 2017).

\section{Theoretical background of study constructs for the proposed model}

Over the years, researchers had developed numerous frameworks to explain user's inclination towards technology adoption based on designated factors or contextual perspectives. In the context of online education, one of the most widely cited frameworks was the technology acceptance model (TAM). Based on Ajzen's (1985) theory of reasoned action (TRA), TAM explored the acceptance behaviour of consumers and the reasons affecting the adoption of new technologies (Davis, 1989). This model suggested that perceived usefulness and perceived ease of use were the main factors that influenced an individual's attitude towards using (ATU) and behavioural intention to use (BI) a technology (Davis, 1986; Davis, 1989). Through the unified theory of acceptance and use of technology (UTAUT), Venkatesh et al. (2003) 
identified performance expectancy, effort expectancy, social influence, and facilitating conditions as the four major aspects influencing BI of consumers to adopt a specific technology. While experience, age, gender, and voluntariness were found to have moderating effects on the acceptance of the technology. UTUAT stated that BI was influenced the most by performance expectancy, effort expectancy, and social influence whereas social influence and facilitating conditions established the use of technology. Many studies have been conducted by applying or extending the original TAM or UTUAT frameworks incorporating additional variables to improve the existing model.

Through expectation confirmation theory (ECT), Oliver (1980) expressed consumer satisfaction as a function of expectation and expectancy disconfirmation with the major constructs being expectations, performance, disconfirmation, and satisfaction. Cheng (2020) explored the switch to online education platforms utilizing attributes such as interactivity, course content quality, and course design quality to measure student's satisfaction. Everett Rogers developed the diffusion of innovation (DOI) Theory (Rogers, 2010). Consumer perception towards innovation characteristics can be comprehended better through DOI Theory. The DOI theory recognized five categories of factors that influenced the adoption of technology. These categories were compatibility, relative advantage, complexity, trialability, and observability (Rogers, 2010). Al-Rahmi et al. (2019) examined student's BI towards online education with an integrated construct of extended TAM and the DOI theory to identify potential factors and understand their effect on perception towards technology adoption.

In the context of online education platforms, the switching intention of consumers towards technology adoption could also be explained through the PPM framework (Lin et al., 2021). The PPM framework originated from the human migration literature which explained the switching/shifting behaviour of humans (Clark et al., 1996). Push, Pull, and Mooring factors were the three primary components of the PPM framework (Bansal et al., 2005). Push factors influenced consumers away from the current technology while pull factors attracted consumers towards the newer technology (Hsu, 2014). The mooring factors included variables that either facilitated or restricted the switching intention of consumers towards technology adoption (Cheng et al., 2019). Extant literature demonstrated the applicability of the PPM framework across varying fields of study ( $\mathrm{Li} \& \mathrm{Ku}, 2018$ ). The PPM framework thus identified the various factors that were responsible for the switch made by an individual towards new technology-based products or services such as online education (Nimako, 2012). Chen and Keng (2019) emphasized that when learners shift towards online education service providers, the changes are essentially a kind of switching behaviour, such that the "push-pull-mooring" theory can be used as a theoretical framework to understand the migration patterns involved.

In this study, the authors attempted to understand and uncover the various perspectives that influence a student's decision to switch to online education channels. In contrast to other adoption theoretical frameworks that explore only the behavioural aspects of technology adoption, the PPM framework does not mandate fixed push, pull, or mooring metrics. The ability of the PPM framework to adapt to specific research goals seemed appropriate for the authors to identify the unique push, 
pull, and mooring factors towards the adoption of online education channels in this study. Thus, the inherent flexibility of the PPM framework empowered the authors to additionally account for environmental and economic factors, which influenced and affected a student's intention and behavioural tendencies in the unique context of the COVID-19 pandemic.

During the COVID-19 pandemic and its associated lockdown, students were pushed towards undertaking online courses (Oerther \& Peters, 2020). One could argue that this was similar to being forced to take up a new technology-based product or service (Liu, 2012). Though, in certain cases, individuals inherently got motivated to switch owing to the explicit benefits of online education (Bozkurt et al., 2020). However, during this technology switch, there was evident contemplation regarding the pros and cons of moving on to the online digital education ecosystem (Hodges et al., 2020). Eventually, an individual student would become a customer and consumer of online digital education (Hiltz \& Turoff, 2005).

The authors had defined three critical antecedent variables in this study. In addition to the online coursework mandated by the student's institutions, the effectiveness and efficiency of learning needed to be enhanced by supplementing the mandatory institutional online education (Crawford et al., 2020). The advent of COVID-19 and the new norms of social distancing required the creation of a new way of teaching as well as tracking and improving students' performance (Teräs et al., 2020). There was a renewed focus on assessing the classroom progress as well as a student's self-personal development (Alhumaid et al., 2020; Crawford et al., 2020). This factor has been termed as the platform knowledge scope (PKS) (Cheng et al., 2019) in this study.

Generally, students choose to be on board online education because they felt that when they sought employment in the industry, they would require a certain skill set that their educational institutions were not providing (Harvey, 2010). Students engaged in such professional education that helped them secure desirable employment post completion of their education (Bhattacharyya \& Nair, 2019). This skill set complemented the current field of study wherein the students had been trying to gain proficiency and enhance the value of their mandated college-level course work (Sahin et al., 2014). Amidst changing times, students often sought an alternative, which during the COVID-19 pandemic became online educational courses (Hodges et al., 2020). This alternate means provided the student's a value for money proposition towards building additional skills and ensuring knowledge development (Vargo et al., 2008). In this study, this factor has been termed alternate media attractiveness (AMA) (Cheng et al., 2019).

Often students were interested to join an online medium because their friends had suggested that a particular online course work content and its associated certification was appropriate and in certain cases viewed as necessary (Cano et al., 2014; Sridhar \& Srinivasan, 2012). It also often transpired that some students undertook online coursework because their friends had completed the same or similar coursework (Alhumaid et al., 2020; Teräs et al., 2020). This influence was conceptualized in this study as normative environmental pressure (NEP) (Cheng et al., 2019; Goffman, 1983). As mentioned earlier, switching to a new technology product or service comprised of both push and pull factors 
(Nimako, 2012). Considering the COVID-19 context, PKS was the push factor while AMA and NEP were the pull factors in this study.

Next, the authors defined mediating variables that were considered in this study. Generally, it was observed that students (like any technology adopter) examined and evaluated their choices (Sajjad et al., 2019). In other words, it entailed which course/courses to undergo online (Shrivastava, 1999). Thus, it involved a comparative analysis of product offerings and services on education (Phillips \& Ochs, 2003). Students contemplated regarding few factors and studied them in detail to arrive at the desired educational product or service of choice (Cooper \& Kleinschmidt, 1995). Students often sought ease of use of the digital online platform as an important aspect (Lee \& Mendlinger, 2011). Students also evaluated how easily they could integrate online offerings with their extant learning endeavours (Lee \& Mendlinger, 2011). Further, the features available to learn from online coursework were also assessed by students to choose the most suitable medium (Jaggars \& Xu, 2016). This factor in this study has been described as decision self efficacy (DSE) (Penn \& Lent, 2019).

It has been noted that often students psychologically became more determined to undertake a specific online course (Reeve, 2012). Sometimes students were inclined to pursue a particular online course with a lot more focus and would up the ante with increased learning efforts dedicated towards an online course (Beqiri et al., 2010). Students thereby became more dedicated to providing time for the online digital learning module (Beaudoin, 2002). This factor has been conceptualized as motivation and intention for switching (MIS) (Chen \& Keng, 2019).

Given the COVID-19 pandemic and the long duration of lockdown, one could understand that over a period some students became inclined to invest increased efforts and dedicate more time to the courses (through the online digital channel) that they were pursuing (Oerther \& Peters, 2020). Because the COVID-19 pandemic was evolving with a longer time horizon of lockdown, students spent time going through the reviews and assessment of online coursework to find out which coursework to do online and which ones not to undertake (Willging \& Johnson, 2009). The end result expected from this was towards improving and expanding the knowledge base of the student (Grouws \& Cebulla, 2000). This has been termed in this research as the intention to adapt for knowledge (IAK) (Chen \& Keng, 2019).

Lastly, the authors defined the dependent variable considered in this study. During the COVID-19 world, students on a more serious and regular note considered online courses as the new normal way of education (Sahu, 2020). Thus, such students would think of online courses as a substitute for classroom teaching (Grouws \& Cebulla, 2000). The time, effort and attention they earlier devoted to classroom teaching were equally provided for online education (Hodges et al., 2020). Thus, this was an essential, existential and substantive switch towards online education (Teräs et al., 2020). This aspect has been conceptually termed in this study as switching behaviour for performance (SBP) (Chen \& Keng, 2019). 


\section{Theoretical deduction of hypothesis for proposed model}

Online education platforms enable the utilization of technological devices, learning tools and internet connectivity for educational usage (Means et al., 2009). Individuals who viewed online education platforms as a contributing factor towards personal development and to achieve better efficiency and effectiveness of learning streamlined their efforts towards leveraging online digital platforms (Appelbaum \& Hare, 1996; Teräs et al., 2020). Further, the majority of such individuals pursue online courses without much contemplation and eagerly activate the bundle of features provided on the online digital platform (Crawford et al., 2020; Wojciechowski \& Palmer, 2005). Tallent-Runnels et al. (2006) added that the persistent increase in technological innovation and internet accessibility has further improved the rationale of switching towards online education platforms. Thus, one can hypothesize that:

H1: Platform knowledge scope (PKS) would positively relate to decision self efficacy (DSE).

Individuals who perceived online digital education platforms as value-adding would also be motivated in choosing and thereby using the online course (Hodges et al., 2020; Teräs et al., 2020). The concept of deprivation, defined as people's feelings about the lack of something and their belief that they should have it, was also relevant to the study context (Rostami et al., 2019). The perception of deprivation was the result of a comparison of potential circumstances with existing circumstances. Hart et al. (2016) suggested that the sense of relative deprivation created by the newer online education platforms (that is, the interactivity, personalization, and economic possibilities represented by those platforms) would encourage people to migrate to them. Thus, one can hypothesize that:

$\mathrm{H} 2$ : Platform knowledge scope (PKS) would positively relate to motivation and intention for switching (MIS).

Experts in education and economics have touted blended or fully online content delivery as a vehicle for expanding access to education (Deming et al., 2015). These online education platforms not only provided information technology infrastructure for hosting online courses but also support educational institutions with the design, production, and delivery of online courses. For each course, the learning outcomes, topics, reading materials, and assignments were standardized with iterative quality assurance from domain experts and psychometric evaluators (Chirikov et al., 2020). With an added benefit of ease of accessibility, such online education platforms thus seemed promising for students to enhance their current skill-level and improve performance. Thus, one can hypothesize that:

H3: Platform Knowledge Scope (PKS) would positively relate to Switching Behaviour for Performance (SBP)

It would be tautological to argue that individuals who displayed higher levels of DSE and MIS characteristics would also be more inclined to consider the online coursework format as the new normal. These individuals considered online education platforms as an apt substitute for classroom teaching during pre-COVID-19 days (Alhumaid et al., 2020; Crawford et al., 2020). This fullthrottle switching meant that such students would thus be more inclined to adapt 
themselves (that is their learning ways) to upskill and expand their knowledge scope (Teräs et al., 2020). Thus, the following hypotheses followed:

H4: Decision self efficacy (DSE) would positively relate to intention to adapt for knowledge (IAK).

H5: Motivation and intention for switching (MIS) would positively relate to intention to adapt for knowledge (IAK)

Loh et al. (2016) suggested that flexibility and better learning outcomes were the most striking perceived benefits of online education platforms. Online learning also enabled learners to gain knowledge and improve skills through synchronous and asynchronous learning applications without time and space limitations (Demir Kaymak \& Horzum, 2013; Wei et al., 2015). Further, Bijker (2012) noticed that students in a learning environment also played a crucial role in technological development. It was observed that there was an intricate relationship between the need to use new e-learning technologies for educational purposes and the capability of its adoption to drive change in the way students want to and are willing to, learn. Thus, one can hypothesize that:

H6: Decision self efficacy (DSE) would positively relate to motivation and intention for switching (MIS)

Students who sought online education courses during the COVID-19 pandemic did so with the idea that after undergoing the online coursework, they would be better positioned to cater to industry expectations post completion of the coursework (Crawford et al., 2020; Sahu, 2020). Online education channels were associated with many-to-many or peer-to-peer mode of activities, highlighting the importance of networked social relations, extensive decentralization, and communal knowledge generation (Peters, 2014). Further, students perceived online education platforms as the medium to hone their skills in the domain of their choice to gain expertise (Alhumaid et al., 2020; Hodges et al., 2020). Thus, one could hypothesize that:

H7: Alternate media attractiveness (AMA) would positively relate to decision self efficacy (DSE)

H8: Alternate media attractiveness (AMA) would positively relate to motivation and intention for switching (MIS)

H9: Alternate media attractiveness (AMA) would positively relate to switching behaviour for performance (SBP).

Students who were influenced by their peers and friends towards undertaking particular coursework online would be highly motivated to complete the recommended coursework (Hodges et al., 2020; Sahu, 2020). Given, the enhanced nature of peer influence, such students would become very motivated to switch to the specific online course from extant indulgences (Alhumaid et al., 2020; Teräs et al., 2020). Being able to learn freely, in control of the learning software, course contents and making use of all features that a student's peer community affords, students were able to break away from their societal position as well as from established educational structures. Thus, online educational platforms enabled students to be emancipated from institutional control (stipulating, for instance, what and how to learn) as well as from prevailing societal and economical models (Oliver, 2015). Thus, the following hypothesis was framed: 
H10: Normative environmental pressure (NEP) would positively relate to Motivation and Intention for Switching (MIS).

Individuals who adapted themselves better towards online education (that is IAK) would be better able to enhance their performance based upon online education (Alhumaid et al., 2020; Crawford et al., 2020; Hodges et al., 2020). Thus, the following hypothesis was developed:

H11: Intention to adapt for knowledge (IAK) would positively relate to switching behaviour for performance (SBP).

The theoretical model for online education conceptualized for this study has been depicted in Fig. 1.

\section{Research methodology}

\section{Research procedure and sample}

Consistent with previous research in the context of the PPM framework, a quantitative technique was adopted to study the PPM framework in the context of online education (Chang et al., 2017). Exploratory factor analysis (on the pilot survey sample) and confirmatory factor analysis (on the main study sample) were used to evaluate the measurement model for the proposed model followed by CB-SEM to develop the structural model (Hair et al., 2017). Based on previous literature related to the PPM model, seven factors were identified in the context of online education (Hsieh et al., 2012). The factors were examined by four academic experts for their relevance to the study context. The experts suggested including relevant measures to decipher

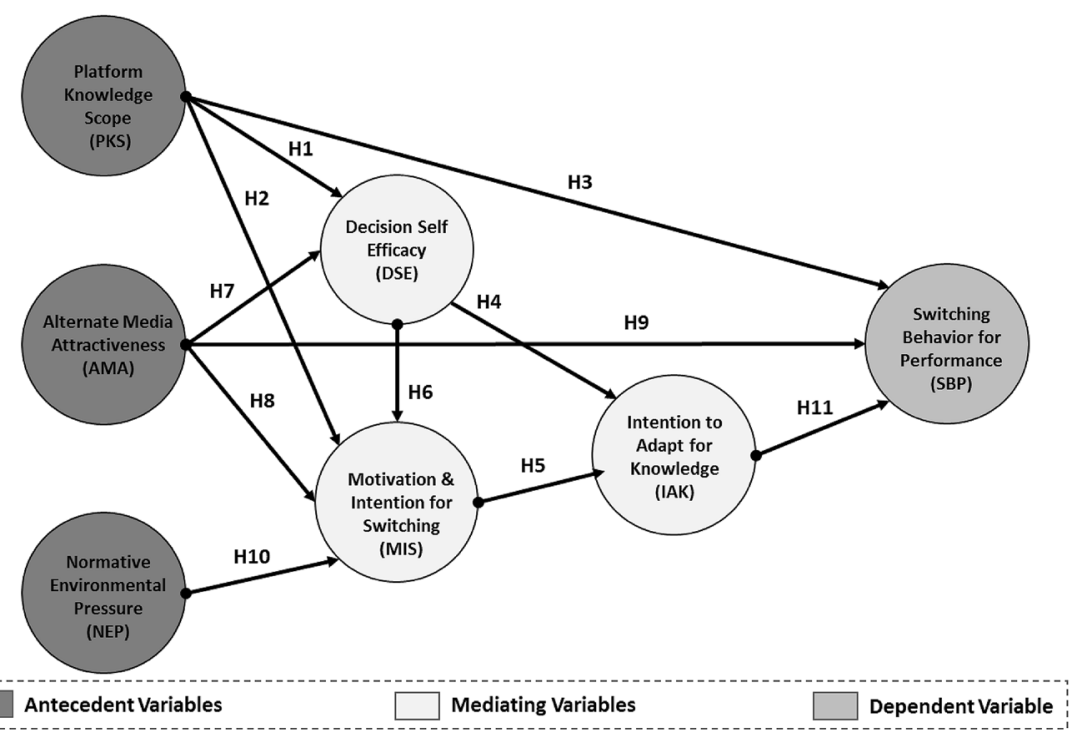

Fig. 1 Theoretical model for online education 
the extent of knowledge sharing potential, upskilling opportunity, peer influence (friends, family, and subject experts), course characteristics and features along with performance expectations for online education. This was in alignment to the previous works of Al-Emran and Teo, (2020); Davey et al. (2019); Zheng et al. (2020). The scale items for the study were adapted from previous studies by Bansal et al. (2005); Bravo and Ostos (2020); Cheng et al. (2019); Sajjad et al. (2020) and Wang et al. (2019). The study questionnaire relevant to all constructs has been provided in appendix table 6 . The items regarding the scales are self-explanatory based upon the literature review presented.

A pilot survey was carried out amongst a sample of 69 students (independent of the main study sample) who had enrolled for online study courses to test the internal consistency of the scale items. The results of the exploratory factor analysis on the pilot survey data indicated that some items did not load strongly on the intended factors. As advocated by Hair et al. (2017), the respective items which had a factor loading of less than 0.5 were dropped. Some of the items that were dropped were related to evaluating self-dependency for pursuing online channels, influence of family/academic experts, and course fee expectations. The reliability of the scale items was examined and found to be satisfactory as indicated in Table 1.

\section{Data analysis strategy}

Based on the refined constructs, the data for the main study was collected from 316 engineering students coming from all over urban India from March to May 2020. A total number of 513 students were approached for the survey out of which 340 responded, thus achieving a response rate of $66.28 \%$. The questionnaires were sent to all the students through e-mail and a follow-up mail was sent after 30 days from the date of the first mail. The students were asked to respond to the statements in the survey on a scale of 1-5 (1 being 'Strongly Disagree' and 5 being 'Strongly Agree'). Since a response rate above $50 \%$ is considered as satisfactory for survey research (Mellahi \& Harris, 2016), the response rate of $66.28 \%$ for this study indicated the generalizability of the study findings (Kellerman \& Herold, 2001). However, 24

Table 1 Reliability coefficient of the constructs

\begin{tabular}{lllll}
\hline Construct & $\begin{array}{l}\text { No. of } \\
\text { items } \\
\text { (original) }\end{array}$ & $\begin{array}{l}\text { No. of } \\
\text { items } \\
\text { retained }\end{array}$ & Cronbach's alpha & $\begin{array}{l}\text { \% of } \\
\text { variance } \\
\text { explained }\end{array}$ \\
\hline Platform knowledge scope (PKS) & 4 & 4 & 0.858 & 70.28 \\
Alternative media attractiveness (AMA) & 4 & 3 & 0.836 & 75.42 \\
Normative environmental pressure (NEP) & 6 & 3 & 0.822 & 77.97 \\
Decision self efficacy (DSE) & 7 & 3 & 0.872 & 79.67 \\
Motivation and intention for switching (MIS) & 5 & 4 & 0.906 & 78.00 \\
Intention to adapt for knowledge (IAK) & 3 & 3 & 0.895 & 82.82 \\
Switching behaviour for performance (SBP) & 3 & 3 & 0.752 & 69.71 \\
\hline
\end{tabular}


responses were not usable because of incomplete responses. Non-probabilistic purposive sampling was used to select the students.

The respondent data from 316 engineering students was tabulated in an MS Excel sheet. The reliability of the questionnaire was calculated which was followed by confirmatory factor analysis (Hair et al., 2017). Confirmatory factor analysis was employed to evaluate the construct and discriminant validity of the constructs as represented in Table 2.

Discriminant validity was further established using the Heterotrait-Monotrait ratio (HTMT) as recommended by Henseler et al. (2015). Values less than 0.85 indicated robust discriminant validity for the study. This has been depicted in Table 3.

Using the maximum likelihood (ML) method of parameter estimation, the structural model was constructed using seven constructs. A range of indices was used to assess the model fit. The analysis demonstrated broadly satisfactory levels of fit (Browne \& Cudeck, 1993; Loo \& Thorpe, 2000) as indicated in Table 4. (Hair et al., 2017). The model fit indices did not differ significantly from the measurement model thus indicating strong model validity.

\section{Data analysis results}

Based on the seven constructs discussed in the earlier sections, the structural model for online education platforms has been presented in Fig. 2.

The structural model revealed the following relationships among the seven constructs-

1. Platform knowledge scope (PKS) positively affected the decision self efficacy (DSE) with $\beta=0.45$, motivation and intention for switching (MIS) with $\beta=0.28$ and switching behaviour for performance (SBP) with $\beta=0.26$.

2. Alternate media attractiveness (AMA) positively affected decision self efficacy (DSE) with $\beta=0.44$, motivation and intention for switching (MIS) with $\beta=0.32$ and switching behaviour for performance (SBP) with $\beta=0.17$.

3. Normative environmental pressure (NEP) positively affected motivation and intention for switching (MIS) with $\beta=0.15$.

4. Decision self efficacy (DSE) was positively related to motivation and intention for switching (MIS) with $\beta=0.22$, and to intention to adopt for knowledge (IAK) with $\beta=0.19$.

5. Motivation and intention for switching (MIS) was positively related to intention to adopt for knowledge (IAK) with $\beta=0.67$.

6. Intention to adopt for knowledge (IAK) was positively related to switching behaviour for performance (SBP) with $\beta=0.43$.

The most rudimentary mediation model was the simple mediation model, in which $X$ was modeled to influence $Y$ directly as well as indirectly through a single intermediary or mediator variable $M$ causally located between $X$ and $Y$. Since multiple mediation paths were involved in this study model, Hayes Model 6 was 


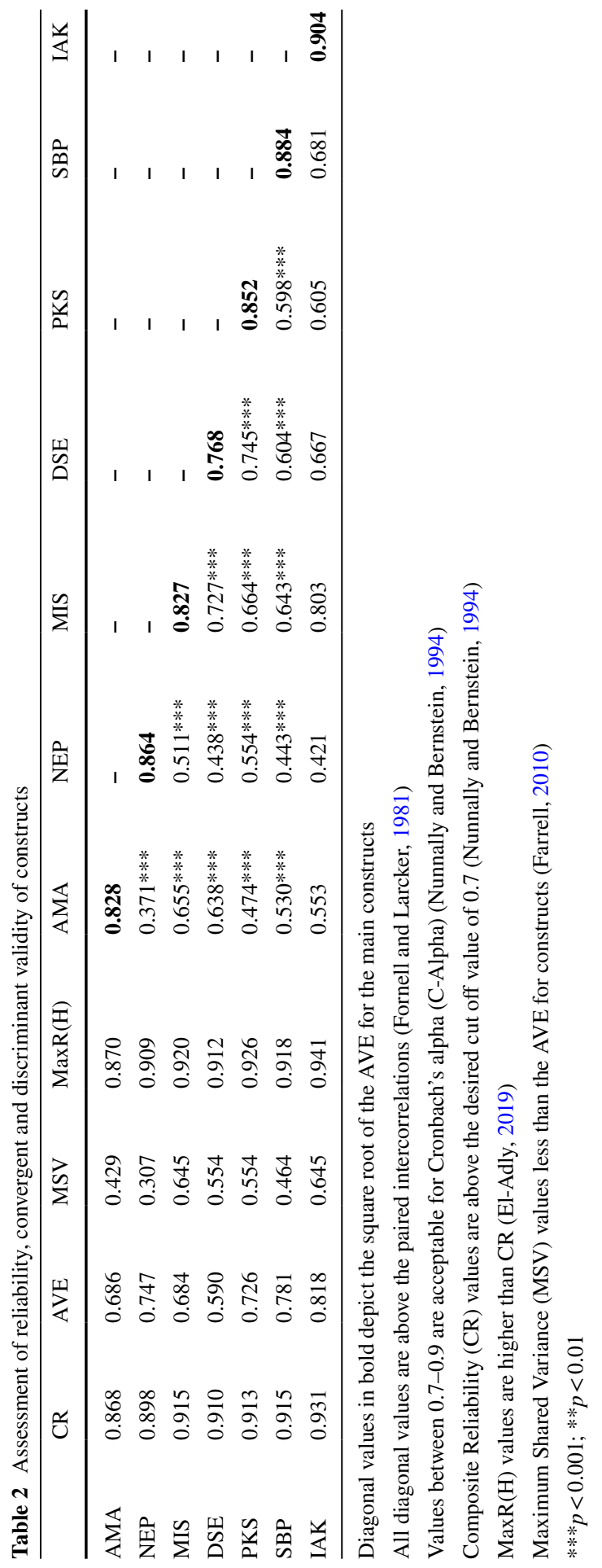


Table 3 HTMT Ratio for assessment of discriminant validity

Table 4 Model fit indices

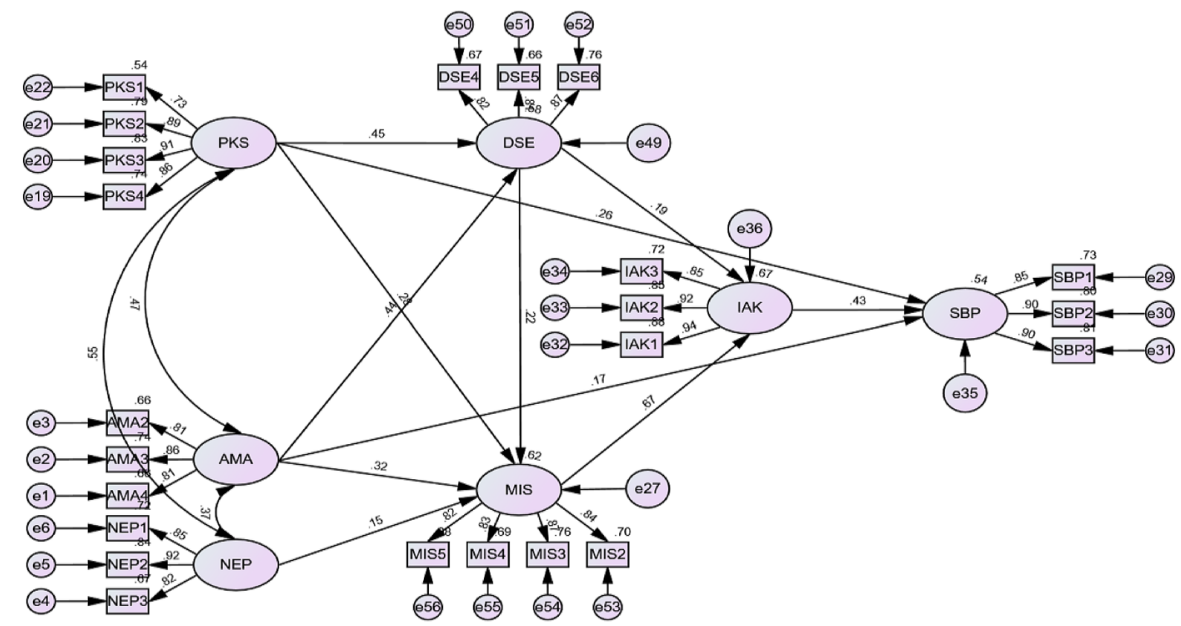

Fig. 2 Structural model for online education

\begin{tabular}{llllllll}
\hline & AMA & NEP & MIS & DSE & PKS & SBP & IAK \\
\hline AMA & - & - & - & - & - & - & - \\
NEP & 0.372 & - & - & - & - & - & - \\
MIS & 0.659 & 0.516 & & - & - & - & - \\
DSE & 0.638 & 0.462 & 0.735 & - & - & - & - \\
PKS & 0.487 & 0.569 & 0.690 & 0.771 & - & - & - \\
SBP & 0.528 & 0.443 & 0.643 & 0.595 & 0.600 & - & - \\
IAK & 0.567 & 0.424 & 0.813 & 0.674 & 0.636 & 0.680 & - \\
\hline
\end{tabular}

$A M A$ alternative media attractiveness, $N E P$ normative environmental pressure, MIS motivation and intention for switching, DSE decision self efficacy, $P K S$, platform knowledge scope, SBP switching behaviour for performance, $I A K$ intention to adapt for knowledge

\begin{tabular}{llll}
\hline Model parameter & $\begin{array}{l}\text { Measure- } \\
\text { ment model }\end{array}$ & Structural model & Desired value \\
\hline Y $^{2} / \mathrm{df}$ & 1.415 & 1.395 & $<5$ \\
GFI & 0.929 & 0.928 & $>0.9$ \\
AGFI & 0.906 & 0.908 & $>0.9$ \\
NFI & 0.952 & 0.951 & $>0.9$ \\
IFI & 0.985 & 0.986 & $>0.9$ \\
TLI & 0.982 & 0.983 & $>0.9$ \\
CFI & 0.985 & 0.985 & $>0.9$ \\
RMSEA & 0.036 & 0.035 & $<0.06$ \\
PCLOSE & 0.995 & 0.997 & $>0.05$ \\
SRMR & 0.0326 & 0.0344 & $<0.05$ \\
\hline
\end{tabular}


used to examine the significance of the paths in the presence of multiple mediators such as DSE, MIS and IAK (Hair et al., 2017; Preacher \& Hayes, 2008). Through process model 6, Hayes (2012) suggested that when K mediators were operating in serial, $\mathrm{X}$ causally influenced all $\mathrm{K}$ mediators, but the mediator $\mathrm{M}_{\mathrm{j}}$ was modeled as causally influenced by mediator $\mathrm{M}_{\mathrm{j}}-1$. Such multiple mediation models had been successfully utilized earlier by Liu and Gal (2011), Van Jaarsveld et al. (2010). In the context of online education platforms, the results of the multiple mediation path analysis for all three antecedent variables are presented

Table 5 Hayes' model 6 path analysis results

\begin{tabular}{|c|c|c|c|c|c|c|}
\hline & & Effect & BootSE & BootLLCI & BootULCI & Result \\
\hline \multicolumn{7}{|c|}{ Relationships between NEP and SBP } \\
\hline Total effect & $\mathrm{NEP} \rightarrow \mathrm{SBP}$ & 0.1273 & 0.0547 & 0.0196 & 0.235 & Supported \\
\hline Direct effect & $\mathrm{NEP} \rightarrow \mathrm{SBP}$ & 0.0814 & 0.0513 & -0.194 & 0.1823 & Not supported \\
\hline \multicolumn{7}{|l|}{ Indirect effect } \\
\hline Ind1 & $\mathrm{NEP} \rightarrow \mathrm{DSE} \rightarrow \mathrm{SBP}$ & 0.0009 & 0.0048 & -0.0086 & 0.0122 & Not supported \\
\hline Ind2 & $\mathrm{NEP} \rightarrow \mathrm{MIS} \rightarrow \mathrm{SBP}$ & 0.0195 & 0.0155 & -0.0045 & 0.056 & Not supported \\
\hline Ind3 & $\mathrm{NEP} \rightarrow \mathrm{IAK} \rightarrow \mathrm{SBP}$ & -0.0022 & 0.0153 & -0.0374 & 0.0236 & Not supported \\
\hline Ind4 & $\mathrm{NEP} \rightarrow \mathrm{DSE} \rightarrow \mathrm{MIS} \rightarrow \mathrm{SBP}$ & 0.0005 & 0.002 & -0.0025 & 0.0059 & Not supported \\
\hline Ind5 & $\mathrm{NEP} \rightarrow \mathrm{DSE} \rightarrow \mathrm{IAK} \rightarrow \mathrm{SBP}$ & 0.0008 & 0.0026 & -0.0048 & 0.0064 & Not supported \\
\hline Ind6 & $\mathrm{NEP} \rightarrow \mathrm{MIS} \rightarrow \mathrm{IAK} \rightarrow \mathrm{SBP}$ & 0.0238 & 0.0116 & 0.0053 & 0.0495 & Supported \\
\hline Ind7 & $\mathrm{NEP} \rightarrow \mathrm{DSE} \rightarrow \mathrm{MIS} \rightarrow \mathrm{IAK} \rightarrow \mathrm{SBP}$ & 0.0006 & 0.002 & -0.0028 & 0.0055 & Not supported \\
\hline \multicolumn{7}{|c|}{ Relationships between AMA and SBP } \\
\hline Total effect & $\mathrm{AMA} \rightarrow \mathrm{SBP}$ & 0.3624 & 0.0667 & 0.2311 & 0.4937 & Supported \\
\hline Direct effect & $\mathrm{AMA} \rightarrow \mathrm{SBP}$ & 0.1385 & 0.0718 & -0.0028 & 0.2799 & Not supported \\
\hline \multicolumn{7}{|l|}{ Indirect effect } \\
\hline Ind 1 & $\mathrm{AMA} \rightarrow \mathrm{DSE} \rightarrow \mathrm{SBP}$ & 0.0215 & 0.0281 & -0.0291 & 0.0845 & Not supported \\
\hline Ind2 & $\mathrm{AMA} \rightarrow \mathrm{MIS} \rightarrow \mathrm{SBP}$ & 0.0385 & 0.0278 & -0.0072 & 0.1032 & Not supported \\
\hline Ind3 & $\mathrm{AMA} \rightarrow \mathrm{IAK} \rightarrow \mathrm{SBP}$ & 0.0176 & 0.0196 & -0.0165 & 0.0599 & Not supported \\
\hline Ind4 & $\mathrm{AMA} \rightarrow \mathrm{DSE} \rightarrow \mathrm{MIS} \rightarrow \mathrm{SBP}$ & 0.0112 & 0.0083 & -0.0022 & 0.03 & Not supported \\
\hline Ind5 & $\mathrm{AMA} \rightarrow \mathrm{DSE} \rightarrow \mathrm{AK} \rightarrow \mathrm{SBP}$ & 0.0176 & 0.0099 & 0.001 & 0.0394 & Supported \\
\hline Ind6 & $\mathrm{AMA} \rightarrow \mathrm{MIS} \rightarrow \mathrm{IAK} \rightarrow \mathrm{SBP}$ & 0.047 & 0.0197 & 0.0136 & 0.0895 & Supported \\
\hline Ind7 & $\mathrm{AMA} \rightarrow \mathrm{DSE} \rightarrow \mathrm{MIS} \rightarrow \mathrm{IAK} \rightarrow \mathrm{SBP}$ & 0.0136 & 0.0063 & 0.0033 & 0.0274 & Supported \\
\hline \multicolumn{7}{|c|}{ Relationships between PKS and SBP } \\
\hline Total effect & $\mathrm{PKS} \rightarrow \mathrm{SBP}$ & 0.3624 & 0.0667 & 0.2311 & 0.4937 & Supported \\
\hline Direct effect & $\mathrm{PKS} \rightarrow \mathrm{SBP}$ & 0.1385 & 0.0718 & -0.0028 & 0.2799 & Not supported \\
\hline \multicolumn{7}{|l|}{ Indirect effect } \\
\hline Ind 1 & $\mathrm{PKS} \rightarrow \mathrm{DSE} \rightarrow \mathrm{SBP}$ & 0.0238 & 0.0307 & -0.0326 & 0.089 & Not supported \\
\hline Ind 2 & $\mathrm{PKS} \rightarrow \mathrm{MIS} \rightarrow \mathrm{SBP}$ & 0.0388 & 0.0279 & -0.0081 & 0.1034 & Not supported \\
\hline Ind3 & $\mathrm{PKS} \rightarrow \mathrm{IAK} \rightarrow \mathrm{SBP}$ & 0.0474 & 0.0336 & -0.0002 & 0.1285 & Not supported \\
\hline Ind4 & $\mathrm{PKS} \rightarrow \mathrm{DSE} \rightarrow \mathrm{MIS} \rightarrow \mathrm{SBP}$ & 0.0123 & 0.0097 & -0.0025 & 0.036 & Not supported \\
\hline Ind5 & $\mathrm{PKS} \rightarrow \mathrm{DSE} \rightarrow \mathrm{IAK} \rightarrow \mathrm{SBP}$ & 0.0195 & 0.0114 & 0.0011 & 0.0452 & Supported \\
\hline Ind6 & $\mathrm{PKS} \rightarrow \mathrm{MIS} \rightarrow \mathrm{IAK} \rightarrow \mathrm{SBP}$ & 0.0474 & 0.0184 & 0.0151 & 0.0874 & Supported \\
\hline Ind7 & $\mathrm{PKS} \rightarrow \mathrm{DSE} \rightarrow \mathrm{MIS} \rightarrow \mathrm{IAK} \rightarrow \mathrm{SBP}$ & 0.0151 & 0.0072 & 0.0032 & 0.0311 & Supported \\
\hline
\end{tabular}


in Table 5. Thus, the proposed influence of antecedent variables (PKS, AMA, NEP) on the dependent variable (SBP) has been captured and presented.

Based on Hayes Model 6, the authors evaluated the significance of the multiple mediating paths. The research findings from this analysis can be summarised as-

1. For PKS, the direct path $(\mathrm{PKS} \rightarrow \mathrm{SBP})$ was insignificant while the indirect paths $(\mathrm{PKS} \rightarrow \mathrm{SBP}$ via DSE, MIS, and IAK) considered for understanding the mediating effect were significant. Hence, the authors could conclude that DSE, MIS, and IAK fully mediated the effect of PKS on SBP. This confirmed the theoretical hypothesis that Platform Knowledge Scope (PKS) would positively relate to Switching Behaviour for Performance (SBP).

2. For AMA, the direct path $(\mathrm{AMA} \rightarrow \mathrm{SBP})$ was considered and found to be insignificant. However, the indirect paths (AMA $\rightarrow$ SBP via DSE, MSE, and IAK) were observed to be significant. Hence, here again, the authors could conclude that DSE, MIS, and IAK fully mediated the effect of AMA on SBP. Thus, the results supported the authors theoretical claim of Alternate Media Attractiveness (AMA) being positively related to Switching Behaviour for Performance (SBP).

3. For NEP, the direct path $(\mathrm{NEP} \rightarrow \mathrm{SBP})$ for NEP was considered which turned out to be insignificant. But the indirect paths (NEP $\rightarrow$ SBP via DSE, MIS, and IAK) were significant. Hence, the authors could conclude that DSE, MIS, and IAK fully mediated the effect of NEP on SBP. These results further strengthen the study theoretical proposition that the mediating variables DSE, MIS, and IAK significantly influenced the switching behaviour of students towards online education platforms.

The mediating effect of these variables on the identified push-pull factors has been aptly demonstrated by these results.

\section{Discussion}

The study findings indicated that during these trying times of the COVID-19 pandemic and associated economic and physical lockdown, students willingly switched from physical classroom to digital online platform. The theoretical model has been presented earlier in Fig. 1. PKSwas an antecedent variable. PKS represented the notion of online education providing a means of securing better learning efficiency and effectiveness as compared to extant classroom education by students. This was in line with the works of earlier scholars (Chen \& Keng, 2019; Sahu, 2020). This was especially so during the COVID-19 pandemic when there was no other option for learning as the economic and physical lockdown with social distancing was followed (Hodges et al., 2020). Appelbaum and Hare (1996) indicated the importance of efficiency and efficacy of student learning for a student's self-development during normal times. Students also choose online digital education platforms because it helped in fulfilling the requirements of the industry and enabled getting better skills at value for money price points. This was indicated by the works of Cox and King 
(2016) and Teräs et al. (2020). These aspects were considered as the second antecedent variable as alternate medium attractiveness (AMA) as mentioned by Wang et al. (2019). Aithal and Aithal (2016) had deliberated regarding the importance of online education platforms catering to the requirements of the industry to improve the skill set of students. During the coronavirus pandemic, the authors found that the need for the same increased significantly. However, the authors found that even during the COVID-19 crisis, students did not view online education as an alternative to classroom learning as also reported by Sasot et al. (2020). Students were influenced by their friends regarding which courses to study (why to study) and such matters (Hallinan \& Williams, 1990). In the present context, this was reported by the studies of Alhumaid et al. (2020) and Teräs et al. (2020). Students were often pursued to undergo a particular online course when others had done the same (Hart et al., 2012). This constituted a third antecedent variable, and it was named NEP (Chen \& Keng, 2019). It was observed by the authors that students were not influenced by their family members, academic experts (like professors), or even the suggestion of industry experts even during the critical and crisis context of COVID-19.

One must note that the antecedent push factor was PKS, and the pull factors were AMA and NEP. Additionally, there were three mediating factors in the empirical model, of which two were the Mooring variables namely DSE and MIS. As discussed by Zimmerman and Kulikowich, (2016), the authors found that DSE was comprised of an individual student's choice of using an online course, which was based upon technologies that were easy to use, was impregnated with interactive features, and which provided the scope to streamline the learning efforts of the students. MIS was constituted of aspects such as students being more determined and devoted to increased efforts to learn from the online course. This was in line with the works of scholars like Crawford et al., (2020), Chen and Keng (2019) and Hodges et al., (2020). The authors found that students were not much inclined to do an online course because it just provided a certification or was an introductory course as well. Students often sought to learn for knowledge as pointed out earlier by Jha and Bhattacharyya (2013). The third mediating variable was the IAK. This was characterized by the research works of Chen and Keng (2019) and Scuotto et al. (2020). It consisted of the student's investment of time and effort towards first searching online courses and adapting themselves to improve their knowledge base. This was earlier pointed by Bhattacharyya (2020).

Finally, when students switched from the physical classroom to online digital channels during the critical period of COVID-19, they were primarily interested in enhancing their performance through learning. Given the prolonged period of the Coronavirus pandemic, students were interested to improve their performance of their course study outcome as if the digital course was the mainstay course. This was similar to the works of Hodges et al., (2020) and Chen and Keng (2019). This was termed as SBP, which was the dependent variable in this study.

Thus, the authors validated the research findings and found that the results converged with extant literature. As proposed in the earlier sections, the validation of all hypotheses has been discussed. PKS was supported to positively affect the DSE with $\beta=0.45$, MIS with $\beta=0.28$ and SBP with $\beta=0.26$. This was in alignment with earlier studies carried out by De Mattos and Laurindo (2017) and Yasumoto and 
Shiu (2007) emphasizing the importance of technology platform knowledge and awareness towards technology adoption. AMA was supported to positively affect DSE with $\beta=0.44$, MIS with $\beta=0.32$ and SBP with $\beta=0.54$. These results validated earlier works of Boyd and Mason (1999), Chuah et al. (2017), and Monsuwé et al. (2004) on the attractiveness of alternate media in technology adoption scenarios. NEP was positively related to MIS with $\beta=0.15$. Yu et al. (2017) and Yang et al., (2007) had suggested similar results regarding the effect of peer influence on technology adoption. As the mediating variable, DSE was supported to being positively related to MIS with $\beta=0.22$; and positively related to intention to adopt for knowledge (IAK) with $\beta=0.19$. Ray et al. (2019), Hsu et al. (2009) and Hsu and Chiu (2004) had confirmed similar results in their studies about the influence of self-efficacy in decision making. Another mediating variable, MIS was supported to being positively related to Intention to Adopt for Knowledge (IAK) with $\beta=0.67$. This result was in alignment with the earlier works of Yu et al., (2017), Dauda and Lee (2015) and Hsieh et al., (2012). Finally, IAK was supported to positively relate to SBP with $\beta=0.43$. Sawang et al., (2013) and Jung et al., (2012) had supported a similar impact of knowledge consumption tendency on the intention to adopt the technology. The empirical model thus established the relationships between the following variables namely PKS and DSE as well as MIS, AMA with DSE and MIS, NEP and MIS, DSE and MIS, DSE and MIS with IAK, PKS, AMA, and IAK with SBP.These relationships were in line with the central tenets of the PPM framework as described by Wang et al. (2019) and Bansal et al. (2005).

\section{Conclusion}

In this study, the authors theoretically contributed by applying the PPM (Bansal et al., 2005; Wang et al., 2019) framework for studying the switching behaviour of students towards online digital platforms during a novel crisis event. In the context of this study, the crisis event being the COVID-19 pandemic and its associated economic and physical lockdown. The authors thus attempted to capture how the COVID-19 crisis and economic lockdown shaped the online digital courses technology delivery channel adoption for engineering students. Earlier studies were conducted focussed on the physical education model during pre-COVID normal times, but there was a scarcity of literature addressing the altered scenario during the COVID-19 outbreak. During the crisis period, there was only one push factor, PKS, two pull factors namely AMA and NEP. In addition, there were two Mooring factors, DSE and MIS. Thus, DSE and MIS acted as the mediating variables along with the variable IAK. The student's switching behaviour was measured via the dependent variable, considered as the SBP. Thus, this research contributed to the existing thread of conversation by initiated by scholars like Wang et al. (2019) and Chen and Keng (2019). This was done by identifying the relevant PPM factors with the added context of the COVID-19 crisis.

Based on this study, online educational firm managers could identify the key factors that must be focused on to respond effectively to the post-COVID-19 opportunities. Managers could introduce initiatives such as adding extensive interactional 
features, taking continuous feedback, improving ease of use, designing dedicated and comprehensive course content, introducing specialized courses with a deep learning environment, ensuring affordable course fees, and many more. During a prolonged crisis like the COVID-19 pandemic and its associated physical lockdown, students shifted towards online education platforms as the mainstay since it was no longer a substitute but the primary and only form of education. Managers were required to be cognizant of this paradigm shift undergone by the students currently. Thus, the authors have emphasized the importance of individual personal characteristics and factors that significantly affect platform choice self-efficacy. Hence, the online education platforms should be better aligned to the students (both as customers and consumers). Better adaptation towards students would lead to better adoption of the online platforms. Thus, managers must play the dual role of facilitating both-adaptation as well as adoption for students.

As part of the future scope, the current study could be extended to incorporate additional elements such as measuring the level of anxiety and its effect on the moderation of the suggested model. Individual factors such as the culture of independence or interdependence could also be factored in this model in future studies. PPM has been applied in many technology adoption contexts so far, but it was seldom applied in the context of a prolonged crisis. This study was a crucial footstep in this novel critical COVID-19 context. During the pandemic and its long-drawn social distancing and physical lockdown, a new conversation of extant frameworks like the PPM (Bansal et al., 2005; Wang et al., 2019) framework on technology adoption was both relevant and important.

Funding There was no funding received for this research.

\section{Declarations}

Conflict of interest The authors declare that they have no conflict of interest.

\section{Appendix}

See Table 6 
Table 6 Study questionnaire

\begin{tabular}{lllllll}
\hline S. No Questions & SD & D & N & A & SA \\
\hline
\end{tabular}

Platform knowledge scope (PKS)

According to me, online learning platforms

1 Contribute a lot to my personal development

2 Helps improve my performance in comparison to classroom teaching

3 Helps improve my effectiveness in comparison to classroom teaching

4 Helps manage my efficiency of learnings in comparison to classroom teaching

Alternative medium attractiveness (AMA)

According to me, online courses should

1 Have content that meet industry requirements

2 Provide better learning value with respect to the price charged

3 Help me become better skilled in the field of my study

Normative environmental pressure (NEP)

I get influenced to study a particular course or certification online when

1 My friends think it is appropriate to undertake

2 My friends consider it necessary to do it

3 My friends have already completed it

Decision self efficacy (DSE)

I am able to motivate and change myself to

1 Experience a suitable online platform with ease

2 Learn to use the features offered by online platforms

3 Streamline my learning efforts with online platforms methodology

Motivation and intentions for switching (MIS)

In the future, when I study online courses, I would like to

1 Increase the time I devote

2 Be determined to take up the course/ certification options

3 Have more focus while choosing the online courses/certifications

4 Increase my level of effort to learn from the online course/certification

Intention to adapt for knowledge (IAK)

In theming few months, I intend to

1 Invest time on online courses for increasing my knowledge base

2 Invest effort on online courses for improving my knowledge base

3 Search different online sources of courses, to improve my current knowledge base

Switching behaviour for performance (SBP)

In future, I will prefer to

1 Consider online courses/certifications as substitute to classroom teaching

2 Increase the time, I devote for online courses relative to the time I devote for classroom teaching

3 Believe that, I will be able to switch to online learning mode substantially 


\section{References}

Aithal, P. S., \& Aithal, S. (2016). Impact of on-line education on higher education system. International Journal of Engineering Research and Modern Education, 1(1), 225-235.

Ajzen, I. (1985). From intentions to actions: A theory of planned behavior. Action control (pp. 11-39). Springer.

Al-Emran, M., \& Teo, T. (2020). Do knowledge acquisition and knowledge sharing really affect e-learning adoption? An empirical study. Education and Information Technologies, 25(3), 1983-1998.

Alhumaid, K., Ali, S., Waheed, A., Zahid, E., \& Habes, M. (2020). COVID-19 \& e-learning: Perceptions $\&$ attitudes of teachers towards e-learning acceptance in the developing countries. Multicultural Education, 6(2), 100-115. https://doi.org/10.5281/zenodo.4060121

Al-Rahmi, W. M., Yahaya, N., Aldraiweesh, A. A., Alamri, M. M., Aljarboa, N. A., Alturki, U., \& Aljeraiwi, A. A. (2019). Integrating technology acceptance model with innovation diffusion theory: An empirical investigation on students' intention to use e-learning systems. IEEE Access, 7, 26797-26809.

Appelbaum, S. H., \& Hare, A. (1996). Self-efficacy as a mediator of goal setting and performance. Journal of Managerial Psychology, 11(3), 33-47.

Bansal, H. S., Taylor, S. F., \& St James, Y. (2005). "Migrating" to new service providers: Toward a unifying framework of consumers' switching behaviors. Journal of the Academy of Marketing Science, 33(1), 96-115.

Beaudoin, M. F. (2002). Learning or lurking?: Tracking the "invisible" online student. The Internet and Higher Education, 5(2), 147-155.

Beqiri, M. S., Chase, N. M., \& Bishka, A. (2009). Online course delivery: An empirical investigation of factors affecting student satisfaction. Journal of Education for Business, 85(2), 95-100.

Bhattacharyya, S. S. (2020). Doctoral research work in strategic management: Perspectives for executives \& parttime candidates. Indian Journal of Industrial Relations, 55(4), 710-720.

Bhattacharyya, S. S., \& Nair, S. (2019). Explicating the future of work: Perspectives from India. Journal of Management Development, 38(3), 175-194.

Bijker, W. E. (2012). The social construction of bakelite: Toward a theory of invention. In W. E. Bijker, T. P. Hughes, \& T. Pinch (Eds.), The Social construction of technological systems: New directions in the sociology and history of technology (Anniversary, pp. 159-187). MIT Press.

Boyd, T. C., \& Mason, C. H. (1999). The link between attractiveness of "extrabrand" attributes and the adoption of innovations. Journal of the Academy of Marketing Science, 27(3), 306-319.

Bozkurt, A., Jung, I., Xiao, J., Vladimirschi, V., Schuwer, R., Egorov, G., Lambert, S., Al-Freih, M., Pete, J., Olcott, D., Jr., \& Rodes, V. (2020). A global outlook to the interruption of education due to COVID-19 Pandemic: Navigating in a time of uncertainty and crisis. Asian Journal of Distance Education, 15(1), 1-126.

Bravo, E. R., \& Ostos, J. (2020). Individual adaptive performance in computer-mediated work: A migration perspective. Information Technology \& People. https://doi.org/10.1108/ITP-02-2019-0089

Browne, M. W., Cudeck, R., Bollen, K. A., \& Long, J. S. (1993). Testing structural equation models. Sage.

Cano, A. E., Mazumdar, S., \& Ciravegna, F. (2014). Social influence analysis in microblogging platforms-a topic-sensitive based approach. Semantic Web, 5(5), 357-372.

Chang, H. H., Wong, K. H., \& Li, S. Y. (2017). Applying push-pull-mooring to investigate channel switching behaviors: M-shopping self-efficacy and switching costs as moderators. Electronic Commerce Research and Applications, 24, 50-67.

Cheng, Y. M. (2020). Students' satisfaction and continuance intention of the cloud-based e-learning system: Roles of interactivity and course quality factors. Education + Training, 62(9), 1037-1059.

Cheng, S., Lee, S.-J., \& Choi, B. (2019). An empirical investigation of users' voluntary switching intention for mobile personal cloud storage services based on the push-pull-mooring framework. Computers in Human Behavior, 92, 198-215.

Chen, Y. H., \& Keng, C. J. (2019). Utilizing the push-pull-mooring-habit framework to explore users' intention to switch from offline to online real-person English learning platform. Internet Research, 29(1), 167-193.

Chirikov, I., Semenova, T., Maloshonok, N., Bettinger, E., \& Kizilcec, R. F. (2020). Online education platforms scale college STEM instruction with equivalent learning outcomes at lower cost. Science Advances, 6(15), eaay5324. 
Chuah, S. H. W., Marimuthu, M., Kandampully, J., \& Bilgihan, A. (2017). What drives gen y loyalty? Understanding the mediated moderating roles of switching costs and alternative attractiveness in the value-satisfaction-loyalty chain. Journal of Retailing and Consumer Services, 36, 124-136.

Clark, D. E., Knapp, T. A., \& White, N. E. (1996). Personal and location-specific characteristics and elderly interstate migration. Growth and Change, 27(3), 327-351.

Cooper, R. G., \& Kleinschmidt, E. J. (1995). Benchmarking the firm's critical success factors in new product development. Journal of Product Innovation Management, 12(5), 374-391.

Cox, S., \& King, D. (2006). Skill sets: An approach to embed employability in course design. Education + Training, 48(4), 262-274.

Crawford, J., Percy, A., \& Kelder, J. A. (2020). JUTLP editorial 17.3: Connection, digital education, and student-centric teaching practice before COVID-19. Journal of University Teaching \& Learning Practice, 17(3), 1-5.

Dauda, S. Y., \& Lee, J. (2015). Technology adoption: A conjoint analysis of consumers' preference on future online banking services. Information Systems, 53, 1-15.

Davey, B., Elliott, K., \& Bora, M. (2019). Negotiating pedagogical challenges in the shift from face-toface to fully online learning: A case study of collaborative design solutions by learning designers and subject matter experts. Journal of University Teaching and Learning Practice, 16(1), 3.

Davis, F.D. (1986). A technology acceptance model for empirically testing new end-user information systems: theory and results. Thesis. Retrieved from: http://dspace.mit.edu/handle/1721.1/15192.

Davis, F. D. (1989). Perceived usefulness, perceived ease of use, and user acceptance of information technology. MIS Quarterly, 13(3), 319-339.

De Mattos, C. A., \& Laurindo, F. J. B. (2017). Information technology adoption and assimilation: Focus on the suppliers portal. Computers in Industry, 85, 48-57.

Deming, D. J., Goldin, C., Katz, L. F., \& Yuchtman, N. (2015). Can online learning bend the higher education cost curve? American Economic Review, 105(5), 496-501.

Demir Kaymak, Z., \& Horzum, M. B. (2013). Relationship between online learning readiness and structure and interaction of online learning students. Educational Sciences, 13(3), 1792-1797.

Dutta, A. (2020). Impact of digital social media on Indian higher education: Alternative approaches of online learning during COVID-19 pandemic crisis. International Journal of Scientific and Research Publications, 10(5), 604-6011.

El-Adly, M. I. (2019). Modelling the relationship between hotel perceived value, customer satisfaction, and customer loyalty. Journal of Retailing and Consumer Services, 50, 322-332.

Ersche, K. D., Lim, T. V., Ward, L. H., Robbins, T. W., \& Stochl, J. (2017). Creature of habit: A selfreport measure of habitual routines and automatic tendencies in everyday life. Personality and Individual Differences, 116, 73-85.

Farrell, A. M. (2010). Insufficient discriminant validity: A comment on Bove, Pervan, Beatty, and Shiu (2009). Journal of Business Research, 63(3), 324-327.

Firth, J., Siddiqi, N., Koyanagi, A., Siskind, D., Rosenbaum, S., Galletly, C., \& Chatterton, M. L. (2019). The lancet psychiatry commission: A blueprint for protecting physical health in people with mental illness. The Lancet Psychiatry, 6(8), 675-712.

Fornell, C., \& Larcker, D. F. (1981). Evaluating structural equation models with unobservable variables and measurement error. Journal of Marketing Research, 18(1), 39-50.

Goffman, E. (1983). The interaction order: American sociological association, 1982 presidential address. American Sociological Review, 48(1), 1-17.

Grouws, D. A., \& Cebulla, K. J. (2000). Improving student achievement in mathematics. Educational practices series. (Vol. 4). UNESCO.

Hair, J. F., Hult, G. T. M., Ringle, C. M., \& Sarstedt, M. (2017). A primer on partial least squares structural equation modeling (PLS-SEM) (2nd ed.). Sage.

Hallinan, M. T., \& Williams, R. A. (1990). Students' characteristics and the peer-influence process. Sociology of Education, 63(2), 122-132.

Hart, S. A. (2016). Precision education initiative: Moving toward personalized education. Mind, Brain, and Education, 10(4), 209-211.

Hart, H. L. A., Hart, H. L. A., \& Green, L. (2012). The concept of law. Oxford University Press.

Harvey, D. (2010). The enigma of capital. Oxford University Press.

Hayes, A. F. (2012). PROCESS: A versatile computational tool for observed variable mediation, moderation, and conditional process modeling. 
Henseler, J., Ringle, C. M., \& Sarstedt, M. (2015). A new criterion for assessing discriminant validity in variance-based structural equation modelling. Journal of the Academy of Marketing Science, 43(1), $115-135$.

Hiltz, S. R., \& Turoff, M. (2005). Education goes digital: The evolution of online learning and the revolution in higher education. Communications of the ACM, 48(10), 59-64.

Hodges, C., Moore, S., Lockee, B., Trust, T., \& Bond, A. (2020). The difference between emergency remote teaching and online learning. Educause Review, 27, 1-12.

Hsieh, J. K., Hsieh, Y. C., Chiu, H. C., \& Feng, Y. C. (2012). Post-adoption switching behavior for online service substitutes: A perspective of the push-pull-mooring framework. Computers in Human Behavior, 28(5), 1912-1920.

Hsu, J. S. C. (2014). Understanding the role of satisfaction in the formation of perceived switching value. Decision Support Systems, 59, 152-162.

Hsu, M. H., \& Chiu, C. M. (2004). Internet self-efficacy and electronic service acceptance. Decision Support Systems, 38(3), 369-381.

Hsu, M. K., Wang, S. W., \& Chiu, K. K. (2009). Computer attitude, statistics anxiety and self-efficacy on statistical software adoption behavior: An empirical study of online MBA learners. Computers in Human Behavior, 25(2), 412-420.

Jaggars, S. S., \& Xu, D. (2016). How do online course design features influence student performance? Computers \& Education, 95, 270-284.

Jha, S., \& Bhattacharyya, S. S. (2013). Learning orientation and performance orientation: Scale development and its relationship with performance. Global Business Review, 14(1), 43-54.

Jung, J., Chan-Olmsted, S., Park, B., \& Kim, Y. (2012). Factors affecting e-book reader awareness, interest, and intention to use. NewMedia \& Society, 14(2), 204-224.

Kellerman, S. E., \& Herold, J. (2001). Physician response to surveys: A review of the literature. American Journal of Preventive Medicine, 20(1), 61-67.

Lee, J. W., \& Mendlinger, S. (2011). Perceived self-efficacy and its effect on online learning acceptance and student satisfaction. Journal of Service Science and Management, 4(03), 243-252.

Li, C. Y., \& Ku, Y. C. (2018). The power of a thumbs-up: Will e-commerce switch to social commerce? Information \& Management, 55(3), 340-357.

Lin, C. H., Zhang, Y., \& Zheng, B. (2017). The roles of learning strategies and motivation in online language learning: A structural equation modeling analysis. Computers \& Education, 113, 75-85.

Lin, C. L., Jin, Y. Q., Zhao, Q., Yu, S. W., \& Su, Y. S. (2021). Factors influence students' switching behavior to online learning under COVID-19 pandemic: A push-pull-mooring model perspective. The Asia-Pacific Education Researcher, 30, 1-17.

Liu, B. (2012). Sentiment analysis and opinion mining. Synthesis Lectures on Human Language Technologies, 5(1), 1-167.

Liu, W., \& Gal, D. (2011). Bringing us together or driving us apart: The effect of soliciting consumer input on consumers' propensity to transact with an organization. Journal of Consumer Research, $38,242-259$.

Loh, C., Wong, D. H., Quazi, A., \& Kingshott, R. P. (2016). Re-examining students' perception of e-learning: An Australian perspective. International Journal of Educational Management, 30(1), 129-139. https://doi.org/10.1108/IJEM-08-2014-0114

Loo, R., \& Thorpe, K. (2000). Confirmatory factor analyses of the full and short versions of the MarloweCrowne social desirability scale. The Journal of Social Psychology, 140(5), 628-635.

Means, B., Toyama, Y., Murphy, R., Bakia, M., \& Jones, K. (2009). Evaluation of evidence-based practices in online learning: A meta-analysis and review of online learning studies. Centre for Learning Technology.

Mellahi, K., \& Harris, L. C. (2016). Response rates in business and management research: An overview of current practice and suggestions for future direction. British Journal of Management, 27(2), 426-437.

Narang, U., Yadav, M. S., \& Rindfleisch, A. (2021). EXPRESS: The "idea advantage": How content sharing strategies impact engagement in online learning platforms. Journal of Marketing Research. https://doi.org/10.1177/00222437211017828

Nimako, S. G. (2012). Linking quality, satisfaction and behaviour intentions in Ghana's mobile telecommunication industry. European Journal of Business and Management, 4(7), 1-17.

Nunnally, J. C., \& Bernstein, I. H. (1994). Psychometric theory (3rd ed.). McGraw-Hill Inc.

Oerther, D. B., \& Peters, C. A. (2020). Educating heads, hands, and hearts in the COVID-19 classroom. Environmental Engineering Science, 37(5), 303-303. 
Oliver, R. L. (1980). A cognitive model of the antecedents and consequences of satisfaction decisions. Journal of Marketing Research, 17(4), 460-469.

Oliver, M. (2015). From openness to permeability: Reframing open education in terms of positive liberty in the enactment of academic practices. Learning, Media and Technology, 40(3), 365-384.

Ozili, P. K., \& Arun, T. (2020). Spillover of COVID-19: Impact on the global economy. SSRN Electronic Journal. https://doi.org/10.2139/ssrn.3562570

Penn, L. T., \& Lent, R. W. (2019). The joint roles of career decision self-efficacy and personality traits in the prediction of career decidedness and decisional difficulty. Journal of Career Assessment, 27(3), $457-470$.

Peters, M. A. (2014). Openness and the intellectual commons (editorial). Open Review of Educational Research, 1(1), 1-7.

Phillips, D., \& Ochs, K. (2003). Processes of policy borrowing in education: Some explanatory and analytical devices. Comparative Education, 39(4), 451-461.

Preacher, K. J., \& Hayes, A. F. (2008). Asymptotic and resampling strategies for assessing and comparing indirect effects in multiple mediator models. Behavior Research Methods, 40(3), 879-891.

Ray, A., Bala, P. K., \& Dasgupta, S. A. (2019). Role of authenticity and perceived benefits of online courses on technology based career choice in India: A modified technology adoption model based on career theory. International Journal of Information Management, 47, 140-151.

Reeve, J. (2012). A self-determination theory perspective on student engagement. In S. L. Christenson, A. L. Reschly, \& C. Wylie (Eds.), Handbook of research on student engagement (pp. 149-172). Springer.

Rogers, E. M. (2010). Diffusion of innovations. Simon and Schuster.

Rostami, M., Ahmadian, L., Jahani, Y., \& Niknafs, A. (2019). The effect of patient satisfaction with academic hospitals on their loyalty. The International Journal of Health Planning and Management, 34(1), e726-e735.

Sahin, A., Ayar, M. C., \& Adiguzel, T. (2014). STEM related after-school program activities and associated outcomes on student learning. Educational Sciences, 14(1), 309-322.

Sahu, P. (2020). Closure of universities due to coronavirus disease 2019 (COVID-19): Impact on education and mental health of students and academic staff. Cureus, 12(4), e7541. https://doi.org/10. 7759/cureus.7541

Sajjad, A., Chu, J., Anwar, M. A., \& Asmi, F. (2020). Between green and gray: Smog risk and rationale behind vehicle switching. Journal of Cleaner Production, 244, 118674.

Sasot, C. F., Nicomedes, C. J. C., Marcos, R. G., Perez, A. J. D., Aganan, J. B., \& Fernando, M. M. M. (2020). A discourse analysis on class cancellations during the COVID-19 pandemic.

Sawang, S., Newton, C., \& Jamieson, K. (2013). Increasing learners' satisfaction/intention to adopt more e-learning. Education + Training, 55(1), 83-105.

Scuotto, V., Beatrice, O., Valentina, C., Nicotra, M., Di Gioia, L., \& Briamonte, M. F. (2020). Uncovering the micro-foundations of knowledge sharing in open innovation partnerships: An intention-based perspective of technology transfer. Technological Forecasting and Social Change, 152(119906), $1-15$.

Shrivastava, P. (1999). Management classes as online learning communities. Journal of Management Education, 23(6), 691-702.

Sintema, E. J. (2020). Effect of COVID-19 on the performance of grade 12 students: Implications for STEM education. Eurasia Journal of Mathematics, Science and Technology Education, 16(7), em1851.

Sridhar, S., \& Srinivasan, R. (2012). Social influence effects in online product ratings. Journal of Marketing, 76(5), 70-88.

Tallent-Runnels, M. K., Thomas, J. A., Lan, W. Y., Cooper, S., Ahern, T. C., Shaw, S. M., \& Liu, X. (2006). Teaching courses online: A review of the research. Review of Educational Research, 76(1), 93-135. https://doi.org/10.3102/00346543076001093

Teräs, M., Suoranta, J., Teräs, H., \& Curcher, M. (2020). Post-COVID-19 education and education technology 'solutionism': A seller's market. Postdigital Science and Education, 2(3), 863-878.

Van Jaarsveld, D. D., Walker, D. D., \& Skarlicki, D. P. (2010). The role of job demands and emotional exhaustion in the relationship between customer and employee incivility. Journal of Management, 36, 1486-1504.

Vargo, S. L., Maglio, P. P., \& Akaka, M. A. (2008). On value and value co-creation: A service systems and service logic perspective. European Management Journal, 26(3), 145-152. 
Venkatesh, V., Morris, M. G., Davis, G. B., \& Davis, F. D. (2003). User acceptance of information technology: Toward a unified view. MIS Quarterly, 27, 425-478.

Wang, L., Luo, X. R., Yang, X., \& Qiao, Z. (2019). Easy come or easy go? Empirical evidence on switching behaviors in mobile payment applications. Information \& Management, 56(7), 103150.

Wei, H. C., Peng, H., \& Chou, C. (2015). Can more interactivity improve learning achievement in an online course? Effects of college students' perception and actual use of a course-management system on their learning achievement. Computers \& Education, 83, 10-21.

Willging, P. A., \& Johnson, S. D. (2009). Factors that influence students' decision to dropout of online courses. Journal of Asynchronous Learning Networks, 13(3), 115-127.

Wojciechowski, A., \& Palmer, L. B. (2005). Individual student characteristics: Can any be predictors of success in online classes. Online Journal of Distance Learning Administration, 8(2), 13.

y Monsuwé, T. P., Dellaert, B. G., \& De Ruyter, K. (2004). What drives consumers to shop online? A literature review. International Journal of Service Industry Management, 15(1), 102-121.

Yang, X., Li, Y., Tan, C. H., \& Teo, H. H. (2007). Students' participation intention in an online discussion forum: Why is computer-mediated interaction attractive? Information \& Management, 44(5), 456-466.

Yasumoto, M., \& Shiu, J. M. (2007). An investigation into collaborative novel technology adoption in vertical disintegration. Annals of Business Administrative Science, 6, 35-70.

Yazdanian, R., West, R., \& Dillenbourg, P. (2020). Keeping up with the trends: Analyzing the dynamics of online learning and hiring platforms in the software programming domain. International Journal of Artificial Intelligence in Education. https://doi.org/10.1007/s40593-020-00231-1

Yu, T. K., Lin, M. L., \& Liao, Y. K. (2017). Understanding factors influencing information communication technology adoption behavior: The moderators of information literacy and digital skills. Computers in Human Behavior, 71, 196-208.

Zheng, B., Lin, C. H., \& Kwon, J. B. (2020). The impact of learner-, instructor-, and course-level factors on online learning. Computers \& Education, 150, 103851.

Zimmerman, W. A., \& Kulikowich, J. M. (2016). Online learning self-efficacy in students with and without online learning experience. American Journal of Distance Education, 30(3), 180-191.

Publisher's Note Springer Nature remains neutral with regard to jurisdictional claims in published maps and institutional affiliations.

Bishwajit Nayak is a Research Scholar who is pursuing a Doctorate in Business Management (Strategy) at the School of Business Management, NMIMS (Mumbai). He currently serves as Senior Vice President-Health Claims and Networking at Future Generali India Insurance Company Limited and has worked for other health insurers throughout his career. Nayak has received several professional diplomas from the Insurance Institute of India and is a Six Sigma Blue Belt. He has published research papers in Business Strategy \& Development; Journal of Systems and Information Technology and International Journal of Sociology and Social Policy. Contact him at bnayak0107@gmail for more information on this research.

Som Sekhar Bhattacharyya is Associate Professor at the National Institute of Industrial Engineering (Mumbai), where he focuses on teaching and research on strategic management. His email address is somdata@gmail.com.

Shaileshwar Goswami is a research scholar in Industrial Safety and Environment at the National Institute of Industrial Engineering (Mumbai).

Shreyash Thakre is a Research Scholar in Industrial Engineering at the National Institute of Industrial Engineering (Mumbai). 